Дворник М. И., Михайленко Е. А., Мокрицкий Б. Я.

M. I. Dvornik, E. A. Mikhailenko, B. Ya. Mokritskii

ПОВЫШЕНИЕ ТВЕРДОСТИ И ТРЕЩИНОСТОЙКОСТИ УЛЬТРАМЕЛКОЗЕРНИСТОГО СПЛАВА WC-8CO-0,4VC-0,4CR ${ }_{3} \mathrm{C}_{2}$ 3А СЧЕТ КОРРЕКТИРОВКИ СОДЕРЖАНИЯ УГЛЕРОДА НА НАЧАЛЬНОЙ СТАДИИ СПЕКАНИЯ

\title{
INCREASING HARDNESS AND FRACTURE TOUGHNESS OF ULTRAFINE ALLOY WC-8CO-0.4VC-0.4CR3C2 BY ADJUSTING THE CARBON CONTENT IN THE SINTERING INITIAL STAGE
}

Дворник Максим Иванович - кандидат технических наук, старший научный сотрудник Федерального государственного бюджетного учреждения науки Института материаловедения Хабаровского научного центра Дальневосточного отделения Российской академии наук (Россия, г. Хабаровск), тел (4212) 226-956. E-mail: Maxxxx80@mail.ru.

Mr. Maksim I. Dvornik - Ph.D. in Engineering, Institute of materials, Far Eastern Branch of Russian Academy of Sciences (Russia, Khabarovsk), tel (4212) 226-956. E-mail: Maxxxx80@mail.ru.

Михайленко Елена Альбертовна - кандидат физико-математических наук, научный сотрудник Федерального государственного бюджетного учреждения науки Института материаловедения Хабаровского научного центра Дальневосточного отделения Российской академии наук (Россия, г. Хабаровск), тел (4212) 226-956. E-mail: Mea80@list.ru.

Ms. Elena A. Mikhailenko - Ph.D. in of Physical Mathematical Sciences, Institute of materials of Far Eastern Branch of Russian Academy of Sciences (Russia, Khabarovsk), tel (4212) 226-956. E-mail: Mea80@list.ru.

Мокрицкий Борис Яковлевич - доктор технических наук, профессор кафедры «Технология машиностроения» Федерального государственного бюджетного образовательного учреждения высшего образования «Комсомольский-на-Амуре государственный технический университет» (Россия, г. Комсомольск-наАмуре), тел (4217)241-117. E-mail: boris@rnastu.ru.

Mr. Boris Ya. Mokritskii - doctor of Engineering, Professor, Technology of mechanical engineering Department, Komsomolsk-on-Amur state technical University (Russia, Komsomolsk-on-Amur), tel (4217)241-117. E-mail: boris@rnastu.ru.

Аннотация. В работе проведены исследования по регулированию концентрации углерода в ультрамелкозернистом твердом сплаве WC-8Co-0,4VC-0,4Cr $\mathrm{C}_{2}$ за счет обработки пористых заготовок в газовой смеси $\mathrm{CO}+\mathrm{CO}_{2}$ на начальной стадии спекания в течение 50 мин при температуре $650{ }^{\circ} \mathrm{C}$. На основе зависимостей концентрации углерода в полученных образцах от концентрации СО в газовой смеси были определены условия увеличения и уменьшения концентрации углерода. Установлено, что восполнение недостатка углерода (0,37 масс.\%) позволяет увеличить твердость (c HV1767 до HV1943) и трещиностойкость (с 5,8 до $8,4 \mathrm{MПа} \sqrt{\mathrm{M})}$ ультрамелкозернистого твердого сплава WC-8Co-0.4VC-0.4C $\mathrm{Cr}_{3} \mathrm{C}_{2}$. Показано наличие градиента твердости по глубине образцов, полученных при обработке в смесях с наибольшей и наименьшей концентрациями СО. Построены зависимости твердости и трещиностойкости от содержания углерода в ультрамелкозернистом сплаве.

Summary. The authors present the adjustment of the carbon concentration in the ultrafine hard alloy WC-8Co$0.4 \mathrm{VC}-0.4 \mathrm{Cr} 3 \mathrm{C} 2$ by treating porous work pieces in the gas mixture $\mathrm{CO}+\mathrm{CO} 2$ at an initial sintering stage during 50 minutes at $650{ }^{\circ} \mathrm{C}$. Based on the dependencies of carbon concentration in the obtained samples from the CO volume concentration in the gas mixture the conditions for increasing and decreasing of carbon concentration were determined. It was revealed that the restoring of carbon lack $(0,37$ mass.\%) can induce the rising hardness (from HV1767 to HV1943) and toughness (from 5.8 to $8.4 \mathrm{MPa} \sqrt{\mathrm{m}}$ ) of ultrafine hard alloy WC-8Co-0.4VC-0.4Cr3C2. The presence of hardness gradient depths for samples obtained by processing in the mixtures with the highest and the lowest concentration of $\mathrm{CO}$ is shown. The dependences of hardness and fracture toughness from the carbon content of the ultrafine alloys were drawn. 
ДвоРнИк М. И., МИХАЙЛЕНКо Е. А., МокРИЦКИй Б. Я.

ПОВЫШЕНИЕ ТВЕРДОСТИ И ТРЕЩИНОСТОЙКОСТИ УЛЬТРАМЕЛКОЗЕРНИСТОГО СПЛАВА WС-8СО-0,4VC-0,4СR3С2 3А СЧЕТ КОРРЕКТИРОВКИ СОДЕРЖАНИЯ УГЛЕРОДА НА НАЧАЛЬНОЙ СТАДИИ СПЕКАНИЯ

Ключевые слова: ультрамелкозернистый твердый сплав, содержание углерода, твердость, трещиностойкость.

Key words: ultrafine hard allot, carbon content, hardness, toughness.

УДК 621.762

\section{Введение}

Вольфрамокобальтовые твердые сплавы были и остаются наиболее распространенным материалом металлорежущих инструментов [1;2]. Около 65 \% всей стружки при механообработке снимается твердосплавным инструментом [3]. Повышение твердости производителями твердых сплавов за счет уменышения среднего диаметра зерен привело к появлению ультрамелкозернистых и наноструктурных твердых сплавов [4; 5; 6], которые значительно превосходят мелкозернистые твердые сплавы по износостойкости $[7 ; 8 ; 9 ; 10 ; 11]$. Основным путем дальнейшего повышения твердости и износостойкости твердых сплавов остается совершенствование технологии спекания.

В процессе получения, хранения и транспортировки поверхность частиц может окисляться, что приводит к потере углерода при спекании $[1 ; 12 ; 13 ; 14]$. Для решения данной проблемы в процессе спекания можно добавить некоторое количество углерода путем подачи газа СО [15; 16]. Из-за более высокой скорости реакции на поверхности данный метод приводит к значительной неравномерности распределения углерода, которую можно устранить дополнительной выдержкой в $\mathrm{CO}_{2}$. В данное время исследователи обратили внимание на то, что градиент содержания углерода по глубине образцов является перспективным способом создания функциональных градиентных твердых сплавов с управляемым распределением свойств [17; 18]. Управлять скоростью реакции и распределением углерода можно путем обработки образцов твердого сплава газовой смесью $\mathrm{CH}_{4}+\mathrm{H}_{2}$ [19]. Перспективным способом управления распределением углерода может быть обработка в газовой смеси $\mathrm{CO}+\mathrm{CO}_{2}$. Экспериментальные данные о влиянии содержания $\mathrm{CO}$ на содержание углерода и свойства получаемых твердых сплавов отсутствуют. Также исследователями не рассмотрена возможность улучшения характеристик ультрамелкозернистого сплава за счет управления содержанием углерода.

Целью работы является создание методики корректировки содержания углерода за счет обработки заготовок в газовых смесях $\mathrm{CO}+\mathrm{CO}_{2}$ для восполнения недостатка или удаления избытка углерода, увеличения твердости и трещиностойкости ультрамелкозернистого твердого сплава.

\section{Методика}

В работе были созданы 8 партий ультрамелкозернистого твердого сплава WC-8Co-0,4VC$0,4 \mathrm{Cr}_{3} \mathrm{C}_{2}$ по 3 образца. Для создания ультрамелкозернистого сплава использовали нанодисперсный порошок WC Hongwu (80 - 100 нм), порошки Co, $\mathrm{VC}$ и $\mathrm{Cr}_{3} \mathrm{C}_{2}$. Смешивание всех порошков для получения ультрамелкозернистого сплава производили в планетарной шаровой мельнице в РМ-400 при частоте 250 об/мин в стаканах объемом 500 мл в течение 40 мин при соотношении масс шаров к порошку 10:1. Гранулирование смесей для получения ультрамелкозернистого сплава производили после смешивания порошка с 2 масс.\% раствора каучука в бензине, прессование этих смесей производили под давлением 360 МПа.

Спекание каждой партии из 3 образцов производили в трубчатой печи Carbolite STF в вакууме. После удаления пластификатора при температуре $650{ }^{\circ} \mathrm{C}$ в течение 50 мин через печь с образцами пропускали газовую смесь $\mathrm{CO}+\mathrm{CO}_{2}$ со скоростью $180 \pm 20$ мл/мин. Расход и концентрацию задавали с помощью цифровых ротаметров massView. Спекание первой партии производили без выдержки в атмосфере $\mathrm{CO}+\mathrm{CO}_{2}$. Объемная доля $\mathrm{CO}$ для партий со 2 по 8 составляла $0,35,65,72,5,75,77,5$ и 80 \% соответственно. Отклонение доли СО в газовой смеси не превышало 0,5 \%. После выдержки спекание прекращали для анализа содержания углерода на анализаторе Horiba EMIA 320V2. После анализа производили окончательное спекание при температуре $1430{ }^{\circ} \mathrm{C}$ в течение 60 мин. 
Полученные образцы размером 20×6,5×5,25 мм были распилены и отшлифованы. Исследование микроструктуры и свойств осуществлялось на перпендикулярном срезе по сечению от края к центру образцов. Пористость рассчитывали на основе плотности, которую определяли гидростатическим взвешиванием. Исследование микроструктуры образцов производили на растровом микроскопе Sigma 300 VP. Средний диаметр зерен WC в сплавах был определен методом секущих. Твердость (HV) измеряли с помощью твердомера HVS-50 при нагрузке P = 294,2 Н на поверхности и в глубине образцов. Погрешность измерения твердости составляет 3 \%. Трещиностойкость $\left(\mathrm{K}_{1 \mathrm{C}}\right)$ рассчитывали по суммарной длине трещин по схеме Палмквиста (ИСО 28079) с помощью уравнения Шетти:

$$
\mathrm{K}_{1 \mathrm{C}}=0,028 \sqrt{\mathrm{HV} \cdot \mathrm{P} / \Sigma \mathrm{l}}
$$

Диаметр кристаллитов WC (областей когерентного рассеивания) был определен по результатам рентгеноструктурного анализа, проведенного на дифрактометре ДРОН-7 при Сu/Ка излучении с длиной волны $\lambda=0,15406$ нм. Размер кристаллитов рассчитан по формуле Стокса-Вильсона:

$$
\beta=\beta_{\mathrm{d}}+\beta_{\varepsilon}=\mathrm{k} \lambda /(d \operatorname{Cos} \theta)+4 \varepsilon \tan \theta,
$$

где $\beta$ - полуширина дифракционного пика на полувысоте (ПШПВ) после инструментальной коррекции; $\beta_{\mathrm{d}}$ и $\beta_{\varepsilon}-$ уширения дифракционных пиков, вызванные малым диаметром кристаллитов, и внутренние напряжения соответственно; $\mathrm{k}$ - константа (0.9); $\mathrm{d}$ и $\varepsilon$ - средний диаметр кристаллитов и внутренние напряжения соответственно; $\theta$ - брэгговский угол.

Анализ был произведен по семи пикам. Инструментальная корректировка была выполнена следующим образом:

$$
\beta(2 \theta)=\text { ПШПВ }
$$

где ПШПВ эксп - полуширина дифракционного пика на полувысоте по результатам анализа; ПШПВ лонного образца гексаборида лантана (LaB 6 - стандартный образец NIST 660b).

\section{Результаты и обсуждение}

Массовая доля углерода в сплаве стехиометрического состава согласно простейшему расчету на основе известных значений молярных масс компонентов в твердом сплаве WC-8Co-0,4VC$0,4 \mathrm{Cr}_{3} \mathrm{C}_{2}$ составляет $5,64 \%$. Окисление порошков кобальта и карбида вольфрама при хранении, транспортировке и измельчении приводит к потере углерода при спекании в результате восстановления оксидов:

$$
2 \mathrm{WO}_{3}+8 \mathrm{WC} \rightarrow 5 \mathrm{~W}_{2} \mathrm{C}+3 \mathrm{CO}_{2} .
$$

По результатам анализа образцов без дополнительной обработки установлено, что содержание углерода в них снижается до 5,27 масс.\%. Обработка заготовок в среде $\mathrm{CO}_{2}$ приводит к дальнейшему снижению концентрации углерода до 5,03 масс.\% в результате следующей реакции:

$$
2 \mathrm{WC}+\mathrm{CO}_{2} \rightarrow \mathrm{W}_{2} \mathrm{C}+2 \mathrm{CO}
$$

После обработки в смесях с содержанием $\mathrm{CO}_{2} 35$ \% содержание углерода так же снижается, но значительно меньше (до 5,17 масс.\%). При недостатке углерода в процессе нагрева до максимальной температуры спекания происходит образование $\eta$-фазы $\left(\mathrm{Co}_{2} \mathrm{~W}_{4} \mathrm{C}\right)$ по следующей схеме: 
ДвоРНИК М. И., МИХАЙЛЕНКо Е. А., МОКРИЦКИЙ Б. Я.

ПОВЫШЕНИЕ ТВЕРДОСТИ И ТРЕЩИНОСТОЙКОСТИ УЛЬТРАМЕЛКОЗЕРНИСТОГО СПЛАВА WC-8CO-0,4VC-0,4CR3С2 3А СЧЕТ КОРРЕКТИРОВКИ СОДЕРЖАНИЯ УГЛЕРОДА НА НАЧАЛЬНОЙ СТАДИИ СПЕКАНИЯ

$$
3 \mathrm{~W}_{2} \mathrm{C}+2 \mathrm{Co} \longrightarrow \mathrm{Co}_{2} \mathrm{~W}_{4} \mathrm{C}+2 \mathrm{WC} .
$$

По результатам травления образцов п-фаза не была выявлена. Это можем быть связано с равномерностью ее распространения и малым размером включений, который может оказаться меньше разрешения оптического микроскопа из-за использования нанодисперсного порошка. Прогнозируемое наличие $\eta$-фазы $\left(\mathrm{Co}_{2} \mathrm{~W}_{4} \mathrm{C}\right)$ было подтверждено лишь на дифрактограмме образца, полученного после обработки заготовки в атмосфере $\mathrm{CO}_{2}$, недостаток углерода в котором был максимальным (см. рис. 1). На остальных дифрактограммах пиков ๆ-фазы так же не выявлено.

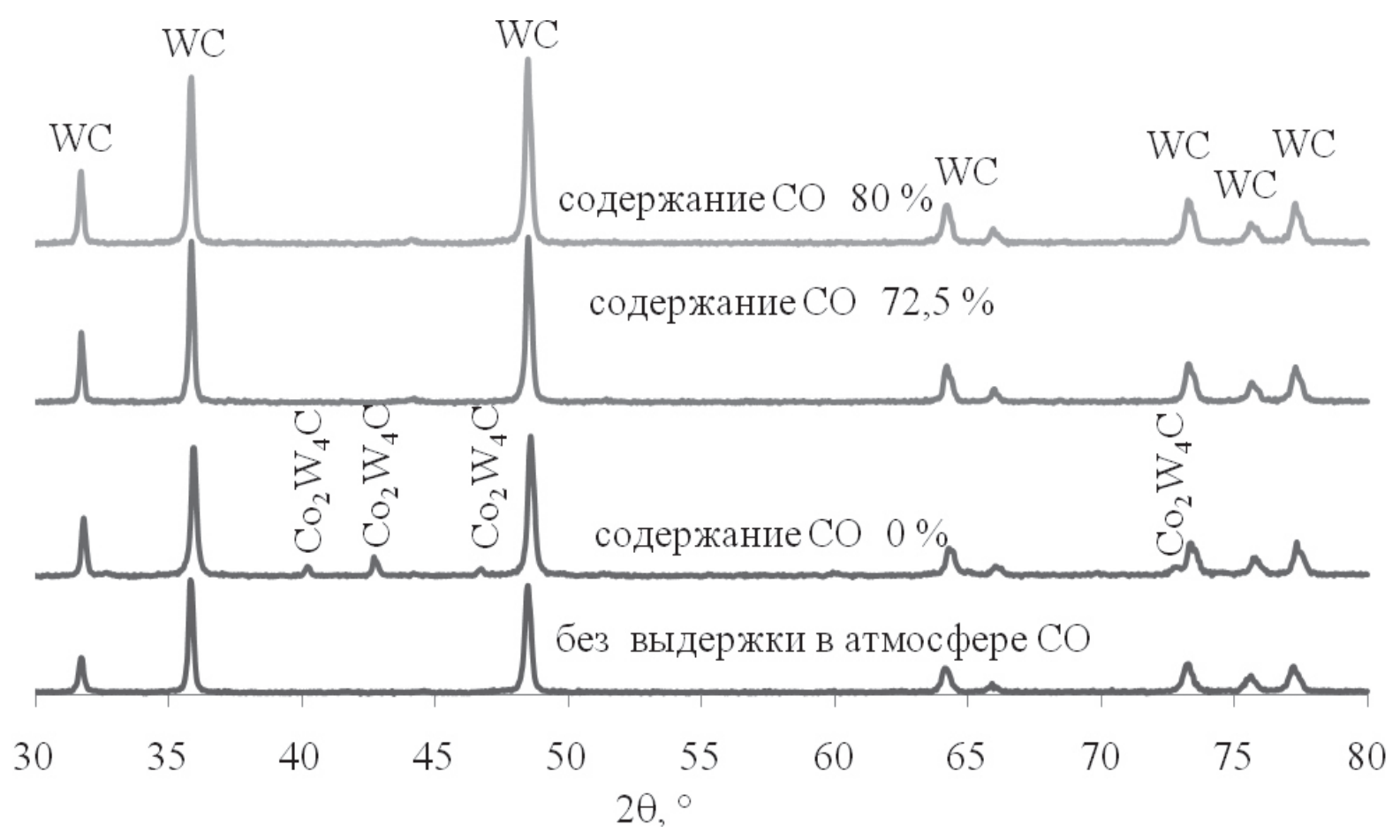

Рис. 1. Дифрактограммы спеченных образцов WC-8Co-0,4VC-0,4Cr $\mathrm{C}_{2}$

При дальнейшем повышении содержания СО в газовой смеси до 65 об.\% и выше равновесие реакции смещается в сторону увеличения концентрации углерода. Разложение СО внутри пор по всему объему прессовки происходит под каталитическим воздействием кобальта. При 65\%-й концентрации СО в газовой смеси содержание углерода оказывается ниже уровня стехиометрического состава. При достижении объемной концентрации СО 72,5 \% содержание углерода достигает стехиометрического состава, а при дальнейшем росте концентрации СО до 80 \% скорость реакции резко возрастает, что приводит к превышению стехиометрической концентрации углерода (см. рис. 2). Концентрация СО при этом в поверхностных слоях остается выше, чем внутри образцов, что приводит к появлению градиента концентрации углерода. Градиент значительно возрастает при увеличении концентрации $\mathrm{CO}$ за счет того, что разлагающийся углерод препятствует диффузионному проникновению газов в глубину образцов. При высокой концентрации $\mathrm{CO}_{2}$ происходит формирование отрицательного градиента в результате повышенной концентрации $\mathrm{CO}_{2}$ вблизи поверхности образцов.

При дальнейшем нагреве до $1430{ }^{\circ} \mathrm{C}$ происходит диффузия углерода внутрь частиц карбида вольфрама и его восстановление по следующей формуле:

$$
3 \mathrm{~W}_{2} \mathrm{C}+2 \mathrm{Co} \longrightarrow \mathrm{Co}_{2} \mathrm{~W}_{4} \mathrm{C}+2 \mathrm{WC} \text {. }
$$




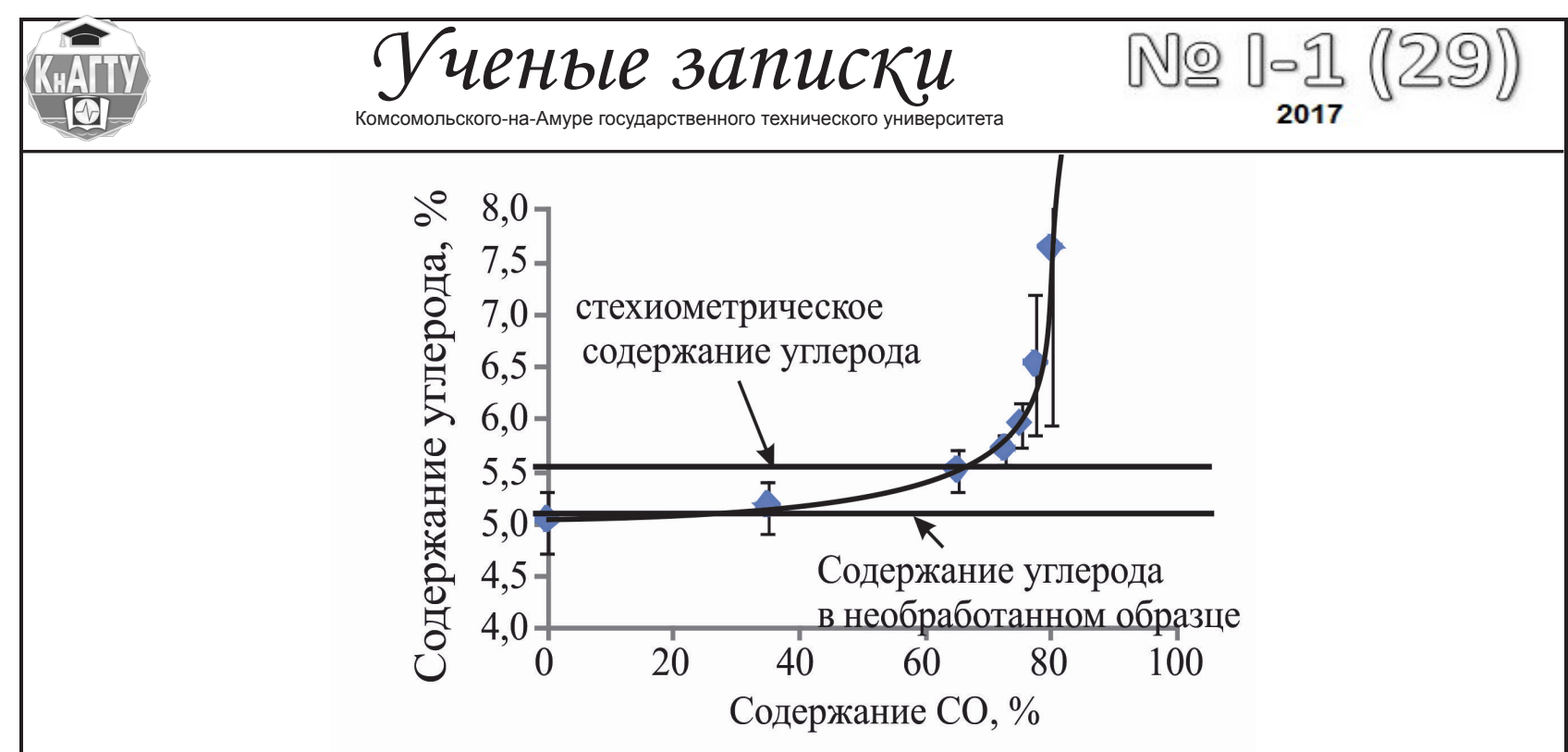

Рис. 2. Зависимость содержания углерода в полученных образцах от содержания $\mathrm{CO}$ в смеси $\mathrm{CO}+\mathrm{CO}_{2}$

Повышение концентрации ๆ-фазы приводит к снижению содержания жидкой фазы на основе кобальта, что затрудняет заполнение пор и в конечном итоге приводит к повышению пористости. Свободный углерод, образующийся при высокой концентрации $\mathrm{CO}$, так же препятствует уплотнению образцов. Включения свободного углерода, обладая пренебрежительно малой плотностью и прочностью, играют ту же роль, что и поры (снижают плотность, твердость и трещиностойкость). На рис. 3 видно, что недостаток углерода и избыток углерода приводят к резкому снижению плотности и повышению пористости. Пористость достигает 4,6 \% у образцов с содержанием свободного углерода 2 масс.\%. Пористость образцов с недостатком углерода $(0,4-$ 0,7 масс.\%) достигает $5-7 \%$.
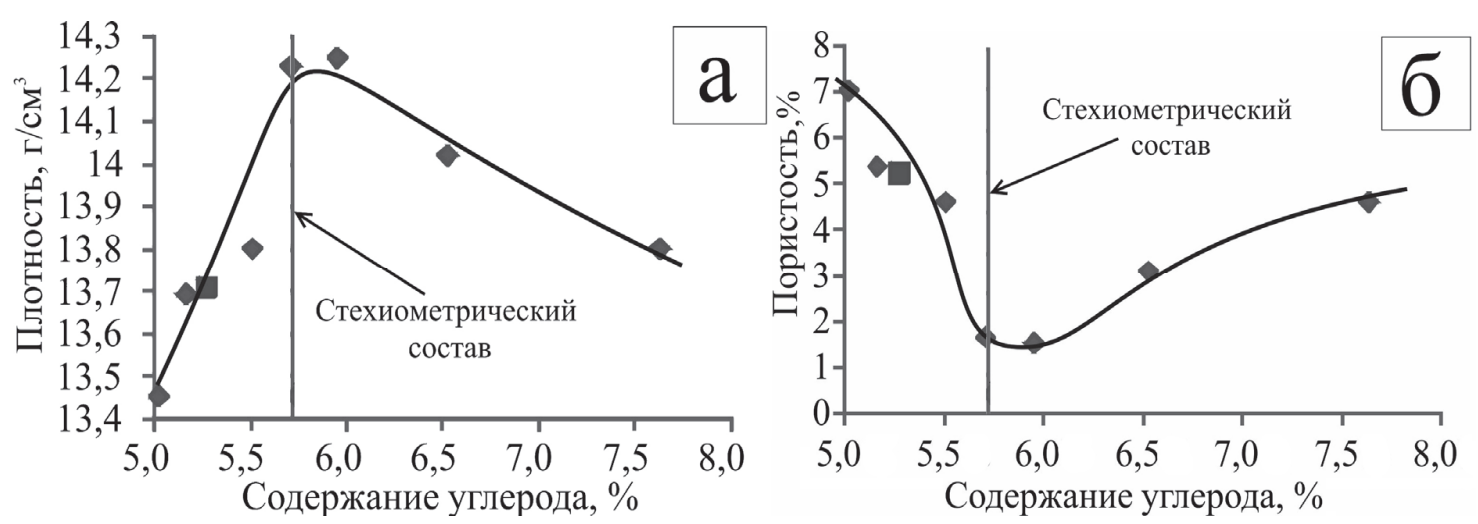

Рис. 3. Зависимости плотности (а) и пористости (б) от содержания углерода в ультрамелкозернистом сплаве $\mathrm{WC}-8 \mathrm{Co}-0,4 \mathrm{VC}-0,4 \mathrm{Cr}_{3} \mathrm{C}_{2}$ после обработки заготовок

$$
\text { в } \mathrm{CO}(\bullet) \text { и без обработки (匹) }
$$

Наименьшей пористостью (1,5 и 1,63 \%) обладают образцы ультрамелкозернистого сплава стехиометрического состава, полученные при объемной концентрации СО 72,5 и 75 \%. Дальнейшее снижение пористости возможно лишь за счет применения дорогостоящих методов спекания с применением давления, либо за счет повышения температуры. Однако последний вариант приведет к ускоренному росту зерен и снижению твердости. 
ДвоРНИК М. И., МИХАЙЛЕНКо Е. А., МОКРИЦКИЙ Б. Я.

ПОВЫШЕНИЕ ТВЕРДОСТИ И ТРЕЩИНОСТОЙКОСТИ УЛЬТРАМЕЛКОЗЕРНИСТОГО СПЛАВА WС-8CO-0,4VС-0,4CR3С2 3А СЧЕТ КОРРЕКТИРОВКИ СОДЕРЖАНИЯ УГЛЕРОДА НА НАЧАЛЬНОЙ СТАДИИ СПЕКАНИЯ

Структура полученных сплавов, представленная на рис. 4, состоит из зерен WC, пространство между которыми заполнено кобальтом. На рис. 4 видно, что в сплавах с наименьшим содержанием углерода, полученных без обработки и обработанных в среде $\mathrm{CO}_{2}$ (см. рис. $4, a, \sigma$ ), доля кобальта (черного цвета) значительно меньше, чем в сплаве стехиометрического состава (см. рис. $4,8)$ и в сплаве с наивысшим содержанием углерода (см. рис. 4,2$)$.
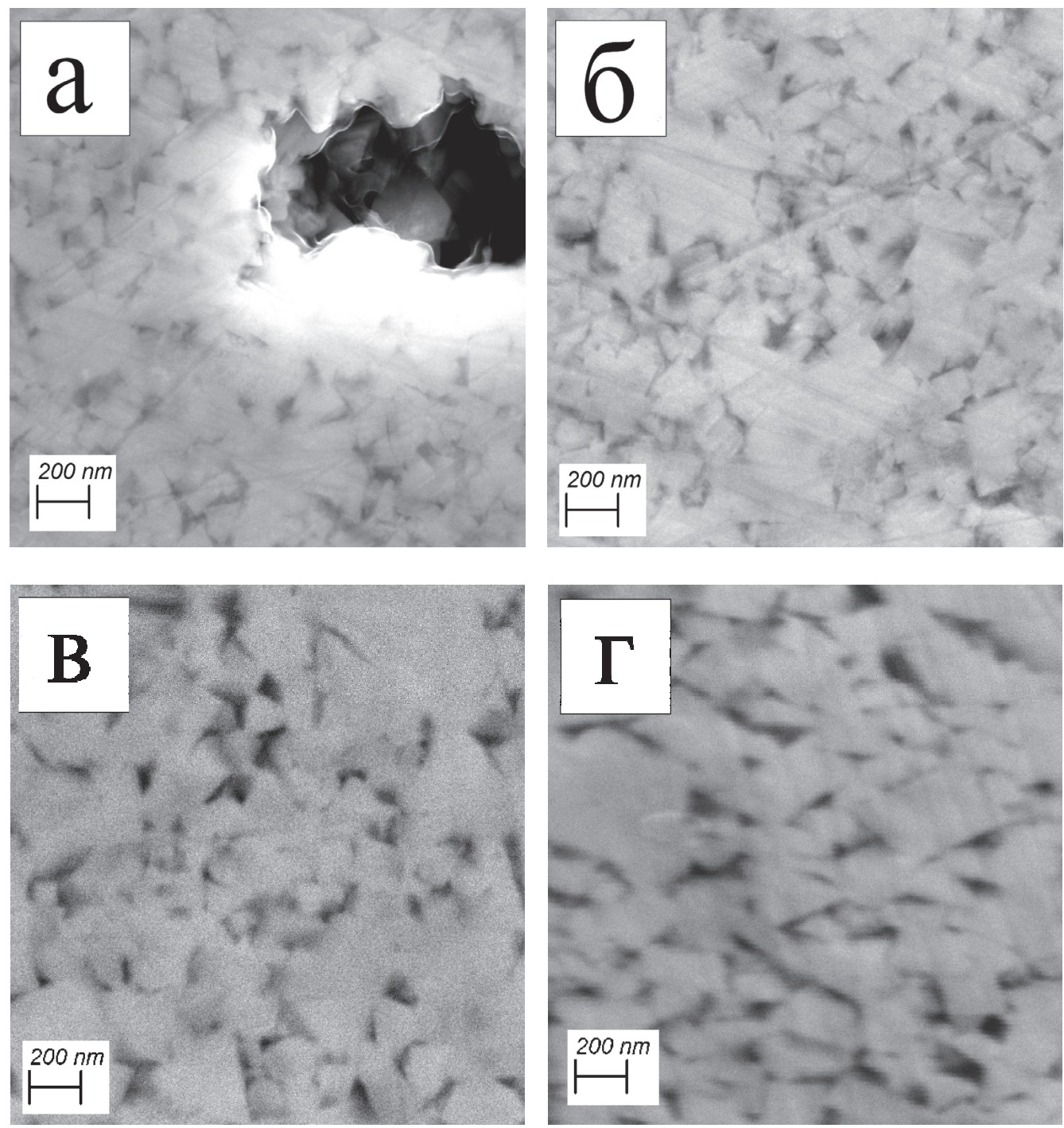

Рис. 4. Микроструктуры образцов, спеченных без выдержки (а), после выдержки в атмосфере $\mathrm{CO}+\mathrm{CO}_{2}$ с содержанием $\mathrm{CO} 0 \%$ (б), $72,5 \%$ (в) и $80 \%$ (г)

Анализ микроструктур (см. табл. 1) показал, что средний диаметр зерен WC в полученных образцах не зависит от содержания углерода и составил 0,37 мкм, что соответствует ультрамелкозернистому сплаву $(0,2-0,5$ мкм). Этот диаметр значительно меньше, чем средний диаметр зерен в широко известных промышленных особомелкозернистых твердых сплавах ВК6ОМ и ВК10ХОМ $(0,8-1$ мкм). 


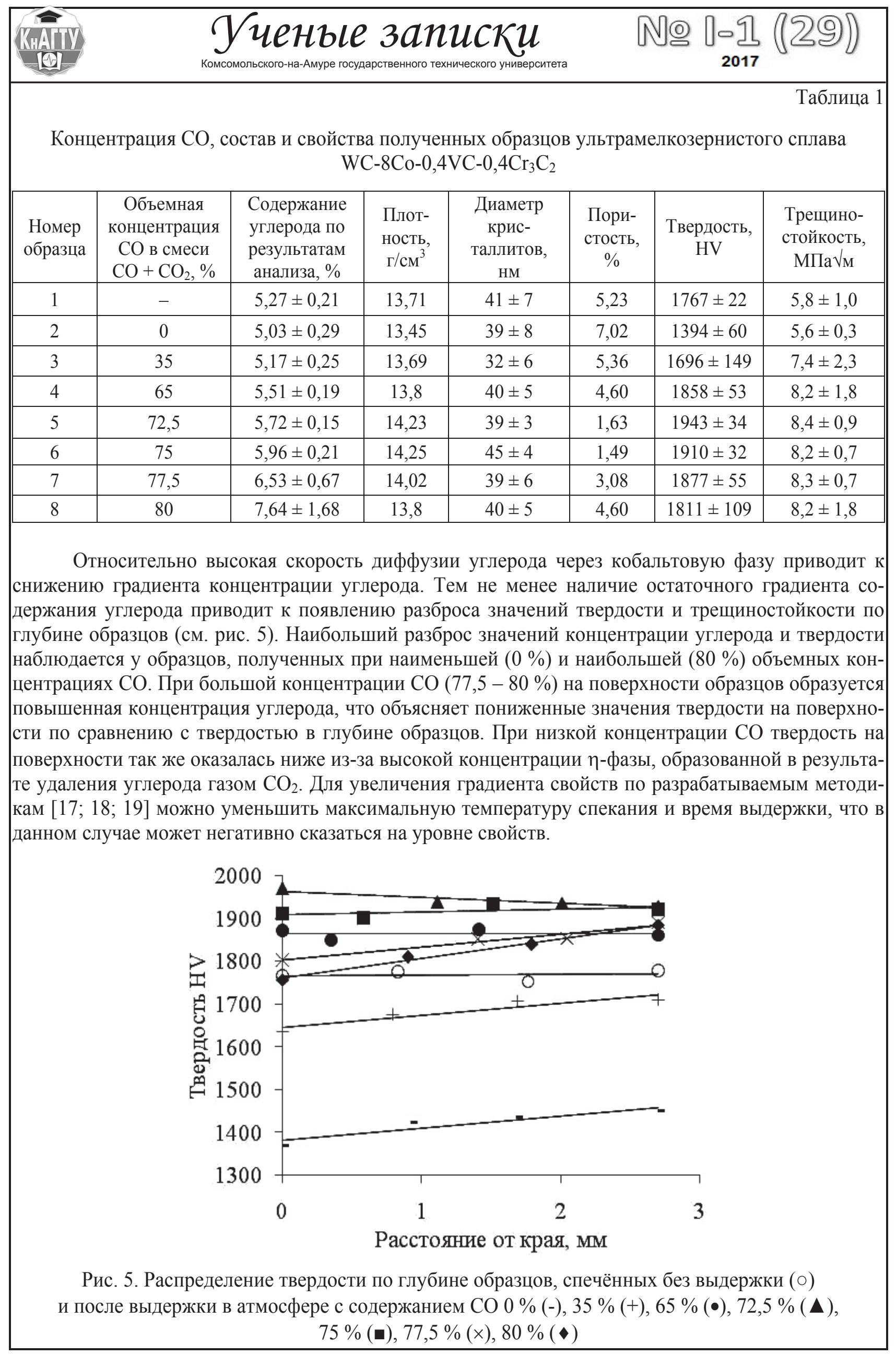


ДвоРНИК М. И., МИХАЙЛЕНКО Е. А., МОКРИЦКИЙ Б. Я.

ПОВЫШЕНИЕ ТВЕРДОСТИ И ТРЕЩИНОСТОЙКОСТИ УЛЬТРАМЕЛКОЗЕРНИСТОГО СПЛАВА WС-8CO-0,4VC-0,4СR3С2 3А СЧЕТ КОРРЕКТИРОВКИ СОДЕРЖАНИЯ УГЛЕРОДА НА НАЧАЛЬНОЙ СТАДИИ СПЕКАНИЯ

На рис. 6, $a$ видно, что твердость значительно увеличивается при увеличении концентрации углерода, уменьшаться начинает, достигнув максимума при стехиометрическом составе. Трещиностойкость так же значительно увеличивается при приближении к стехиометрическому составу. Избыток углерода в сплавах, содержащих более 6 масс.\% углерода, не приводит к значительному падению трещиностойкости (см. рис. 6, б). Это может быть связано как с изменением состава кобальтовой фазы, в которой растворяется больше углерода, так и с влиянием включений свободного углерода на процесс деформации сплавов в зоне распространения трещины. Также можно заметить, что в сплавах с избытком и недостатком углерода наблюдается разброс значений трещиностойкости. Этот разброс вызван наличием градиента свойств по глубине в результате неравномерного распределения углерода.
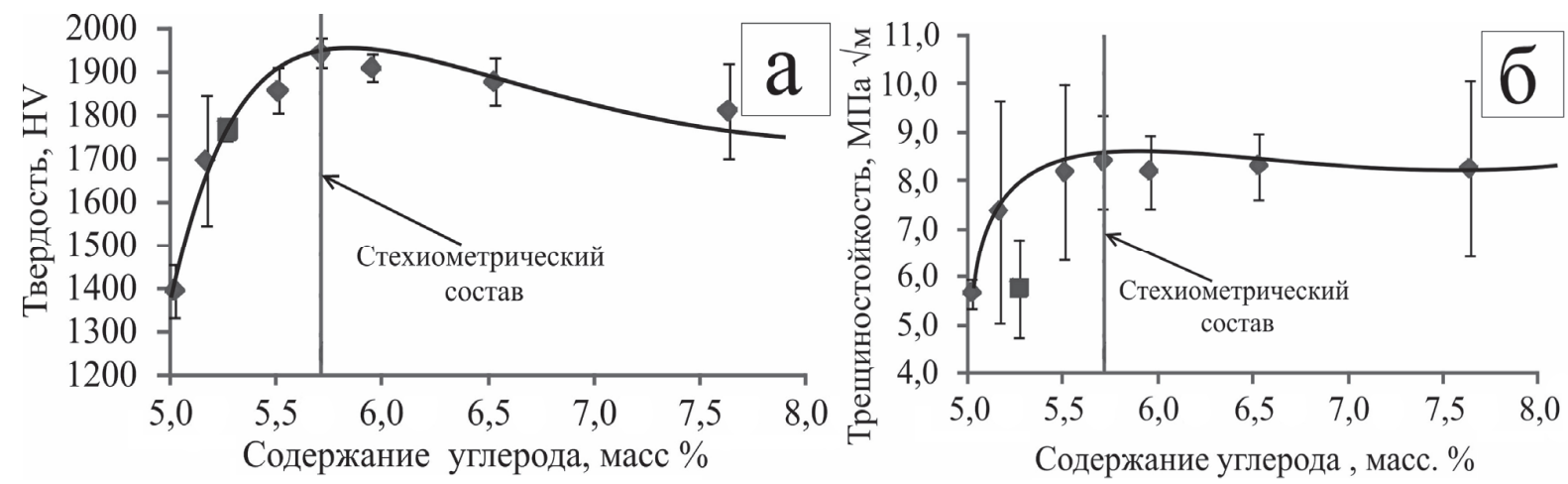

Рис. 6. Зависимости твердости (а) и трещиностойкости (б) от содержания углерода в сплавах, полученных после обработки в газовой смеси (•) и без обработки (๘)

Благодаря малому размеру зерна значения твердости полученных после восполнения углерода образцов стехиометрического состава (партия № 5) значительно превосходят значения твердости субмикронных твердых сплавов $[1 ; 2 ; 3]$. Полученные образцы так же превосходят по твердости ультрамелкозернистые аналоги, полученные жидкофазным спеканием [20], горячим прессованием [21], электроискровым и индукционным спеканием [22; 23]. Некоторое отставание в трещиностойкость можно объяснить большим размером зерен у аналогов $[21 ; 23 ; 22]$. Таким образом, предложенная методика корректировки содержания углерода позволяет без особых затрат добиться повышения характеристик твердых сплавов.

\section{Выводы}

Установлено, что обработка пористых заготовок ультрамелкозернистого твердого сплава WC-8Co-0,4VC-0,4Cr $\mathrm{C}_{2}$ в атмосфере $\mathrm{CO}+\mathrm{CO}_{2}$ на начальной стадии спекания позволяет увеличивать и уменьшать содержание углерода в твердом сплаве за счет увеличения и уменьшения концентрации СО. В частности, выдержка в газовой смеси с концентрацией СО 72,5 \% при температуре $650{ }^{\circ} \mathrm{C}$ в минуту пористой заготовки с недостатком углерода $(0,37 \%)$ в течение 50 мин позволяет восполнить этот недостаток и добиться снижения пористости (с 5,23 до 1,63 \%), увеличения твердости (с HV1767 до HV1943) и трещиностойкости (с 5,8 до 8,4 MПа $\sqrt{M}_{\mathrm{M}}$ ) ультрамелкозернистого твердого сплава WC-8Co-0,4VC-0,4Cr $\mathrm{C}_{2}$ после спекания. При увеличении содержания $\mathrm{CO}$ от 65 до 80 \% происходит увеличение концентрации углерода в полученных образцах с 5,51 до 7,64 масс.\%. При уменьшении концентрации СО с 35 до 0 \% наблюдается уменьшение концентрации углерода. Недостаток углерода приводит к резкому снижению твердости и трещиностойкости образцов из-за формирования хрупкой ұ-фазы и соответствующего роста пористости. Избыток углерода так же снижает твердость и в меньшей степени трещиностойкость полученных сплавов. Повышенная скорость реакций образования и удаления углерода в приповерхностных слоях во время обработки приводит к формированию градиентов твердости в сплавах со значительным избытком и недостатком углерода. 


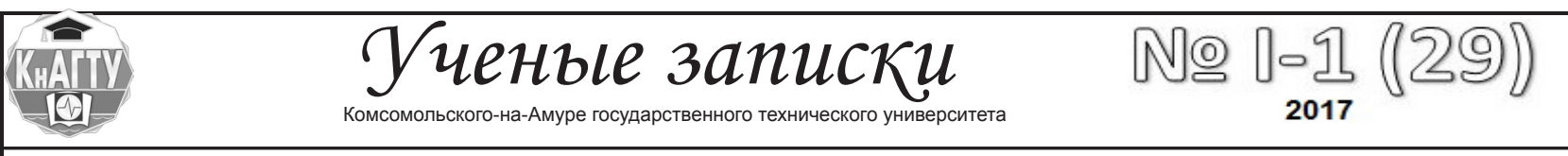

Снимки на растровом микроскопе получены в Дальневосточном центре электронной микроскопии на базе ИБМ ДВО РАН.

\section{ЛИТЕРАТУРА}

1. Панов, В. С. Технология и свойства спеченных твердых сплавов и изделий из них / В. С. Панов, А. М. Чувилин. - М.: МИСИС, 2001. -452 с.

2. Третьяков, В. И. Основы металловедения и технологии производства спеченных твердых сплавов В. И. Третьяков. - М.: Металлургия, 1976. -512 с.

3. Григорьев, С. Н. Технологические методы повышения износостойкости контактных площадок режущего инструмента / С. Н. Григорьев, В. П. Табаков, М. А. Волосова. - Старый Оскол: ТНТ, 2011. - 380 с.

4. Synthesis, sintering, and mechanical properties of nanocrystalline cemented tungsten carbide - A review $/$ Z. Zak Fang, Xu Wang, Taegong Ryu, Kyu Sup Hwang, H. Y. Sohn // Int. Journal of Refractory Metals \& Hard Materials, 27. - 2009. - P. 288-299.

5. Mukhopadhyay, A. Consolidation-microstructure-property relationships in bulk nanoceramics and ceramic nanocomposites: a review / A. Mukhopadhyay, B. Basu // International Materials Reviews. - 2007. - Vol. 52. N. 5. - P. 257-288.

6. Панов, В. С. Тенденции развития технологии ультрадисперсных и наноразмерных твердых сплавов WC-Co / В. C. Панов, А. А. Зайцев // Известия вузов. Порошковая металлургия и функциональные покрытия. - 2014. - № 3. - С. 38-48.

7. Submicron and ultrafine grained hardmetals for microdrills and metal cutting inserts / B. Gille, K. Szesny, Dreyer, H. van den Berg, J. Schmidt, T. Gestrich, G. Leitner // International Journal of Refractory Metals \& Hard Materials. - 2002, 20. - P. 3-22.

8. Hiroyuki Saito. Effects of Co content and WC grain size on wear of WC cemented carbide / Hiroyuki Saito, Akira Iwabuchi, Tomoharu Shimizu. - Wear, 2006, 261. - P. 126-132.

9. Jia, K. Sliding wear of conventional and nanostructured cemented carbides / K. Jia, T. E. Fischer. - Wear, vol. 203-204. - P. 310-318.

10. Дворник, М. И. Сравнительный анализ износостойкости субмикронного твердого сплава WC-8Co-1 Cr3С2 и традиционных твердых сплавов при сухом трении / М. И. Дворник, А. В. Зайцев // Перспективные материалы. - 2015. - № 5. - С. 34-41.

11. Дворник, М. И. Сравнительный анализ микроабразивной износостойкости традиционных твердых сплавов и субмикронного твердого сплава WC-8Co- $1 \mathrm{Cr}_{3} \mathrm{C}_{2} / \mathrm{M}$. И. Дворник, Б. Я. Мокрицкий, А. В. Зайцев // Вопросы материаловедения. - 2015. - № 1(81). - С. 45-51.

12. S. Xiaoliang, Y. Hua, W. Sheng, S. Gangqin, D. Xinglong. Influences of Carbon Content on the Properties and Microstructure of Ultrafine WC-10Co Cemented Carbide // Journal of Wuhan University of Technology-Mater. 2007. - P. 473-476.

13. Gwan-Hyoung Lee, Shinhoo Kang. Sintering of nano-sized WC-Co powders produced by a gas reductioncarburization process // Journal of Alloys and Compounds. - 2006. - Vol. 419, Issues 1-2. - P. 281-289.

14. Chongbin Wei, Xiaoyan Song, Jun Fu, Xiaosen Lv, Haibin Wang, Yang Gao, Shixian Zhao, Xuemei Liu. Effect of Carbon Addition on Microstructure and Properties of WC-Co Cemented Carbides // J. Mater. Sci. Technol. -2012. - Vol. 28(9). - P. 837-843.

15. Дворник, М. И. Повышение прочности и твердости субмикронного твердого сплава WC-8\%Со$1 \% \mathrm{Cr} 3 \mathrm{C} 2$ за счет докарбидизации в процессе спекания / М. И. Дворник, А. В. Зайцев, Т. Б. Ершова // Вопросы материаловедения. - 2011. - № 4(68). - С. 81-88.

16. Дворник, М. И. Влияние дефектов на прочность субмикронного твердого сплава WC-8\% Co- $1 \% \mathrm{Cr}_{3} \mathrm{C}_{2} /$ М. И. Дворник, А. В. Зайцев, Т. Б. Ершова // Материаловедение. - 2012. - № 3. - С. 19-23.

17. O. Eso, Z. Fang, A. Griffo. Liquid phase sintering of functionally graded WC-Co composites. International Journal of Refractory Metals and Hard Materials, 2005. - Vol. 23, Issues 4-6. - P. 233-241.

18. Peng Fan, Z. Zak Fang, Jun Guo. A review of liquid phase migration and methods for fabrication of functionally graded cemented tungsten carbide. Int. Journal of Refractory Metals and Hard Materials 36 (2013). - P. 2-9.

19. I. Konyashin, B. Ries, F. Lachmann, A. T. Fry. A novel sintering technique for fabrication of functionally gradient WC-Co cemented carbides. J Mater Sci, 2012. - Vol. 47, issue 20. - P. 7072-7084.

20. Прочность на изгиб и микротвердость твердых сплавов WC-8\%Со на основе порошков разной дисперсности / А. С. Курлов, А. А. Ремпель, А. Leenaers, S. Van Der Bergh // Материаловедение. - 2009. - № 4. C. $18-21$. 
ДвоРНИК М. И., МИХАЙЛЕНКо Е. А., МокРИЦКИй Б. Я.

ПОВЫШЕНИЕ ТВЕРДОСТИ И ТРЕЩИНОСТОЙКОСТИ УЛЬТРАМЕЛКОЗЕРНИСТОГО СПЛАВА WС-8СО-0,4VC-0,4СR3С2 3А СЧЕТ КОРРЕКТИРОВКИ СОДЕРЖАНИЯ УГЛЕРОДА НА НАЧАЛЬНОЙ СТАДИИ СПЕКАНИЯ

21. M. Sherif El-Eskandarany, Amir A. Mahday, H.A. Ahmed , A.H. Amer. Synthesis and characterizations of ball-milled nanocrystalline WC and nanocomposite WC-Co powders and subsequent consolidations. Journal of Alloys and Compounds 312 (2000) 315-325.

22. Hwan Cheol Kim, In Kyoon Jeong, In Jin Shon, In Yong Ko, Jung Mann Doh. Fabrication of WC-8 wt.\%Co hard materials by two rapid sintering processes. International Journal of Refractory Metals and Hard Materials, 2007. - Vol. 25, Issue 4. - P. 336-340.

23. Hwan-Cheol Kim, In-Jin Shon, Jin-Kook Yoon, Jung-Mann Doh. Consolidation of ultra fine WC and WC-Co hard materials by pulsed current activated sintering and its mechanical properties. International Journal of Refractory Metals and Hard Materials, 2007. - Vol. 25, Issue 1. - P. 46-52. 